\title{
KARAKTERISTIK GELANGGANG BILANGAN BULAT DAN PENGAITANNYA DENGAN TIGA STRUKTUR KHUSUS DAERAH INTEGRAL
}

\author{
Eka Susilowati \\ Fakultas Keguruan dan Ilmu Pendidikan, Universitas PGRI Adi Buana Surabaya \\ eka250@gmail.com
}

\begin{abstract}
Abstrak
Himpunan $\overline{\mathbb{Z}}$ merupakan himpunan semua bilangan bulat aljabar. Himpunan $\overline{\mathbb{Z}}$ membentuk suatu struktur aljabar, yaitu gelanggang. Number field $K$ merupakan lapangan perluasan dari $\mathbb{Q}$ dengan derajat berhingga. Ketika himpunan $\overline{\mathbb{Z}}$ dan $K$ diiriskan maka membentuk suatu gelanggang yang dinamakan gelanggang bilangan bulat (ring of integer) dari number field $K$.

Suatu bilangan bulat $\mathbb{Z}$ dapat difaktorisasi dan faktorisasinya tunggal. Ketunggalan faktorisasi ini memotivasi suatu daerah integral yang dinamakan daerah faktorisasi tunggal. Himpunan bilangan bulat $\mathbb{Z}$ juga merupakan daerah ideal utama. Beberapa sifat yang dimiliki daerah ideal utama memotivasi suatu daerah integral dengan struktur berbeda yang dinamakan daerah Dedekind. Daerah Dedekind D adalah suatu daerah integral yang merupakan gelanggang Noetherian, tertutup secara integral dalam lapangan hasil baginya, dan setiap ideal prima dalam $D$ merupakan ideal maksimal. Oleh karena daerah Dedekind ternyata mempunyai sifat yang serupa dengan $\mathbb{Z}$, maka daerah Dedekind dapat dipandang sebagai abstraksi dari $\mathbb{Z}$.

Dalam makalah ini, dibahas mengenai karakteristik gelanggang bilangan bulat $O_{K}$ memenuhi karakteristik pada daerah Dedekind. Namun, jika gelanggang bilangan bulat $O_{K}$ dikaitkan daerah ideal utama dan daerah faktorisasi tunggal maka memunculkan suatu hubungan yang tidak ekuivalen.
\end{abstract}

Kata kunci: daerah Dedekind, daerah faktorisasi tunggal, daerah ideal utama, gelanggang Noetherian 


\section{PENDAHULUAN}

Pada pertengahan abad 19, Kummer memperkenalkan suatu daerah integral dengan struktur khusus yang dinamakan daerah faktorisasi tunggal. Kummer mendefinisikan bahwa suatu daerah integral dinamakan daerah faktorisasi tunggal jika setiap elemennya dapat difaktorisasi dalam bentuk hasil kali elemen tak tereduksi yang bersifat tunggal.

Selanjutnya, dikenal pula struktur daerah integral yang berbeda dengan daerah faktorisasi tunggal. Apabila suatu daerah integral yang setiap ideal di dalamnya merupakan ideal utama maka daerah integral tersebut dinamakan daerah ideal utama.

Pada tahun 1871, Kummer dan Dedekind memperkenalkan suatu struktur daerah integral lain yang dinamakan daerah Dedekind. Daerah Dedekind ini termotivasi dari beberapa sifat yang dimiliki daerah ideal utama. Sifat yang dimaksud adalah daerah integral tersebut merupakan gelanggang Noetherian, tertutup secara integral, dan setiap ideal prima merupakan ideal maksimal, maka daerah integral tersebut dinamakan daerah Dedekind.

Bilangan bulat aljabar merupakan perumuman dari bilangan bulat. Bilangan bulat aljabar dalam number field $\mathbb{Q}$ merupakan elemen dalam $\mathbb{Z}$, yang lebih luas dari number field lain $K$, yang memuat lebih banyak bilangan bulat aljabar. Semua irisan antara himpunan bilangan bulat aljabar dan number fieldnya membentuk gelanggang yang dinamakan gelanggang bilangan bulat $O_{K}$.

Pada artikel ilmiah ini, dipaparkan gelanggang bilangan bulat $O_{K}$ yang dikaitkan dengan daerah ideal utama, daerah faktorisasi tunggal, dan daerah Dedekind. Namun untuk mengaitkan ketiganya, dipaparkan mengenai faktorisasi dalam gelanggang bilangan bulat kuadratik $\mathbb{Z}(\sqrt{d})$ yang merupakan kasus khusus dari gelanggang bilangan bulat $O_{K}$.

\section{METODE PENELITIAN}

Metode dan langkah - langkah penelitian yang dilakukan dalam penelitian ini diantaranya:

1) Memelajari konsep bilangan bulat aljabar, number field, gelanggang bilangan bulat $O_{K}$, dan faktorisasi dalam gelanggang bilangan bulat kuadratik $\mathbb{Z}(\sqrt{d})$.

2) Memelajari sifat - sifat dari gelanggang bilangan bulat $O_{K}$.

3) Memelajari konsep dasar daerah Dedekind dikaitkan dengan daerah ideal utama.

4) Memelajari keterkaitan gelanggang bilangan bulat $O_{K} \quad$ dengan daerah Dedekind dan selanjutnya 
dihubungkan dengan daerah ideal utama dan daerah faktorisasi tunggal.

\section{DASAR TEORI}

\subsection{Daerah Ideal Utama dan Daerah Faktorisasi Tunggal}

Definisi 3.1.1. Suatu daerah integral $R$ dinamakan daerah ideal utama jika setiap ideal di dalam $R$ merupakan ideal utama.

Definisi 3.1.2. Diberikan daerah integral D. Daerah integral D dinamakan daerah faktorisasi tunggal jika memenuhi :

1) Setiap $p \in D-\{0\}$ bukan unit dapat dinyatakan sebagai hasil kali sejumlah berhingga elemen iredusibel.

2) Jika $p_{1} p_{2} \ldots p_{r}$ dan $q_{1} q_{2} \ldots q_{s}$ dua macam faktorisasi dari suatu elemen $p \in D$ dengan $p_{i}, q_{i}$ elemen iredusibel maka $r=s$, dan apabila perlu dengan mengubah urutan, diperoleh $p_{i}$ berasosiasi dengan $q_{i}$

Teorema 3.1.3. Diberikan $D$ daerah ideal utama dan $a \in D-\{0\}, \quad a$ bukan unit. Setiap elemen a dapat dinyatakan sebagai hasil kali elemen - elemen iredusibel.

Teorema 3.1.4 Setiap daerah ideal utama merupakan daerah faktorisasi tunggal.

\subsection{Gelanggang Noetherian}

Di dalam gelanggang, pasti memiliki ideal minimal dirinya sendiri, atau ideal tak sejati. Jika suatu gelanggang memiliki ideal lebih dari satu, maka dapat dihubungkan ideal yang satu dengan ideal yang lain yang dimiliki ideal tersebut. Ketika ideal - ideal tersebut membentuk rangkaian naik dalam suatu gelanggang, namun memiliki elemen maksimal, maka membentuk struktur gelanggang yang baru, yang dinamakan gelanggang Noetherian.

\section{Definisi 3.2.1 Jika $R$ adalah gelanggang dan setiap rangkaian naik ideal - ideal di dalam $R$ yaitu $I_{1} \subset I_{2} \subset \ldots$ terdapat $r$ sedemikian sehingga $I_{r}=I_{s}$ untuk setiap $s \geq r$ maka $R$ dinamakan gelanggang Noetherian.}

Untuk menunjukkan suatu gelanggang merupakan gelanggang Noetherian tidak selalu langsung menggunakan definisi. Alternatif lain yang dapat dilakukan dan bisa jadi mempermudah dalam pembuktian, untuk menunjukkan suatu gelanggang merupakan gelanggang Noetherian dengan menggunakan karakteristik gelanggang Noetherian sebagaimana dijelaskan dalam teorema berikut : 
Teorema 3.2.2 Jika $R$ gelanggang maka pernyataan berikut ekuivalen :

1) $R$ Noetherian.

2) Setiap koleksi tak kosong dari ideal - ideal di $R$ mempunyai elemen maksimal.

3) Setiap ideal di $R$ dibangun secara berhingga.

Proposisi 3.2.3. Setiap daerah ideal utama $D$ merupakan gelanggang Noetherian.

\subsection{Gelanggang Bilangan Bulat}

Definisi 3.3.1. Diberikan $K$ merupakan lapangan perluasan dari $\mathbb{Q}$. Elemen $\alpha \in K$ disebut bilangan bulat aljabar (algebraic integer) jika $\alpha$ integral atas $\mathbb{Z}$, yaitu jika $\alpha$ merupakan akar dari suatu polinomial monik dengan koefisien dalam $\mathbb{Z}$.

Proposisi 3.3.2. Himpunan $\overline{\mathbb{Z}}$ yang memuat semua bilangan bulat aljabar merupakan gelanggang, yaitu penjumlahan dan pergandaan dua bilangan bulat aljabar juga merupakan bilangan bulat aljabar.

Berdasarkan Definisi 3.3.1., bilangan bulat aljabar merupakan akar dari polinomial monik dengan koefisien dalam $\mathbb{Z}$. Jika koefisien dari polinomial monik diperluas dalam $\mathbb{Q}$ maka akar polinomial monik tersebut dikatakan bilangan aljabar.
Definisi 3.3.3. Diberikan $K$ lapangan perluasan dari $\mathbb{Q}$. Lapangan $K$ dikatakan number field jika $K$ merupakan lapangan perluasan dari $\mathbb{Q}$ dengan derajat berhingga.

Bilangan bulat aljabar yang dihimpun dan diiriskan dengan number fieldnya membentuk gelanggang sebagaimana dijelaskan dalam definisi berikut :

Definisi 3.3.4. Gelanggang bilangan bulat (ring of integer) dari number field $K$ adalah gelanggang yang terdiri dari elemen - elemen yang merupakan irisan dari $K$ dan $\overline{\mathbb{Z}}$, dinotasikan sebagai berikut :

$O_{K}=K \cap \overline{\mathbb{Z}}=\{x \in K \mid x$ adalah bilangan aljabar $\}$

Sebagai contoh, lapangan $\mathbb{Q}$ merupakan number field dengan derajat 1 . Gelanggang bilangan bulat dari $\mathbb{Q}$ adalah $\mathbb{Z}$.

Apabila diberikan lapangan $\mathbb{Q}(\sqrt{d})$ dengan $d$ square free - integer, ternyata dapat ditemukan gelanggang bilangan bulat $\mathbb{Z}(\sqrt{d})$ dalam $\mathbb{Q}(\sqrt{d})$ dengan syarat tertentu. Berikut akan dibahas kriteria suatu gelanggang bilangan bulat $\mathbb{Z}(\sqrt{d})$ dalam $\mathbb{Q}(\sqrt{d})$.

Teorema 3.3.5. Diberikan $\mathbb{Q} \sqrt{d}$ lapangan perluasan berhingga dari $\mathbb{Q}$ dengan $d$ square - free integer. Dalam hal ini, $d \neq 0 \bmod 4$. Jika $d \equiv 2 \bmod 4$ atau $d \equiv 3 \bmod 4$ maka 
$O_{\mathbb{Q}(\sqrt{d})}=\mathbb{Z}(\sqrt{d})$.

Dengan menggunakan Teorema 3.3.5 maka dapat ditemukan dengan mudah contoh - contoh lain gelanggang bilangan bulat berbentuk $\mathbb{Z}(\sqrt{d})$.

\section{Contoh 3.3.6.}

1. Diberikan number field $\mathbb{Q}(\sqrt{-5})$ dan gelanggang $\mathbb{Z}(\sqrt{-5})$ dengan . Karena -1 merupakan square free integer dan $-5 \equiv 3 \bmod 4$, maka berdasarkan Teorema 3.3.5, gelanggang bilangan bulat dari number field $\mathbb{Q}(\sqrt{-5})$ adalah $\mathbb{Z}(\sqrt{-5})$.

2. Diberikan number field $\mathbb{Q}(\sqrt{5}) \quad$ dan gelanggang $\mathbb{Z}(\sqrt{5})$ dengan 5 merupakan square free - integer. Karena tidak berlaku $5 \equiv 3 \bmod 4$ atau $5 \equiv 2 \bmod 4, \quad$ berdasarkan Teorema 3.3.5 bukan merupakan gelanggang bilangan bulat dari $\mathbb{Q}(\sqrt{5})$.

3.

\section{HASIL \\ PEMBAHASAN \\ DAN}

Definisi 4.1. (Dummit Foote, 2004, hal 691) Diberikan gelanggang komutatif $S$ dengan unity dan $R$ merupakan gelanggang bagian dari $S$.

1) Suatu elemen $s \in S$ disebut integral atas $R$ jika $s$ merupakan akar dari polinomial monik di dalam $R[x]$.

2) Gelanggang $S$ disebut perluasan integral dari $R$ jika untuk setiap $s \in S$ adalah integral atas $R$. Dalam hal ini, gelanggang $R$ dikatakan tertutup secara integral (integrally closed) di dalam $S$.

Definisi 4.2. (William Stein, 2005, hal 29) Daerah integral $R$ dikatakan tertutup secara integral di dalam lapangan hasil bagi $S$, jika untuk setiap $\alpha$ di dalam lapangan hasil bagi $S$ dan $\alpha$ merupakan akar dari polinomial monik $f \in R[x]$ maka $\alpha \in R$.

Proposisi 4.3. (Rotman, 2003, hal 925) Diberikan $D$ daerah integral dan $F$ adalah lapangan hasil bagi dari D. Jika $D$ daerah faktorisasi tunggal maka $D$ tertutup secara integral. Jika $D$ daerah ideal utama maka D tertutup secara integral.

Definisi 4.4 (William Stein, Hal 30) Daerah integral $D$ disebut daerah Dedekind (Dedekind domain) jika D gelanggang Noetherian, tertutup secara integral dalam lapangan hasil baginya, dan ideal prima tak nol dari D merupakan ideal maksimal.

Tanpa menunjukkan tiga karakteristik daerah Dedekind, dapat ditentukan suatu daerah integral merupakan daerah Dedekind, sebagaimana dijelaskan proposisi berikut : 
Proposisi 4.5 (Dummit Foote, Hal 764) Setiap daerah ideal utama $D$ merupakan daerah Dedekind.

\subsection{KAITAN ANTARA GELANGGANG \\ BILANGAN \\ DENGAN DEDEKIND}

Lemma 4.6. Diberikan gelanggang bilangan bulat (ring of integer) dari number field $K$. Gelanggang $O_{K} \cap \mathbb{Q}=\mathbb{Z}$ dan $\mathbb{Q} O_{K}=K$.

Lemma 4.7. Jika $\alpha$ merupakan bilangan aljabar, maka terdapat bilangan bulat tak nol $m$ sedemikian sehingga ma merupakan bilangan bulat aljabar.

Akibat 4.8. Jika $K$ merupakan number field, maka $K$ merupakan lapangan hasil bagi dari $O_{K}$.

Lemma berikut ini menjelaskan karakteristik dari gelanggang bilangan bulat.

Lemma 4.9. Jika $K$ merupakan number field maka gelanggang $O_{K}$ tertutup secara integral.

Lemma 4.10. Diberikan gelanggang bilangan bulat $O_{K}$. Ideal prima tak nol dari $O_{K}$ merupakan ideal maksimal.

Proposisi 4.11. Jika $O_{K}$ merupakan gelanggang number (number ring) dan I ideal tak nol dalam $O_{K}$, maka gelanggang hasil bagi $O_{K} / I$ berhingga.

Akibat 4.12. Gelanggang bilangan bulat $O_{K}$ merupakan gelanggang Noetherian.

Berdasarkan Lemma 4.9, Lemma 4.10., dan Akibat 4.12., gelanggang bilangan bulat $O_{K}$ merupakan daerah Dedekind.

\subsection{KAITAN ANTARA GELANGGANG BILANGAN BULAT DENGAN DAERAH IDEAL UTAMA}

Definisi 4.13. Diberikan lapangan $\mathbb{Q}(\sqrt{d})$ dengan d square - free integer. Elemen $\quad \alpha \in \mathbb{Q}(\sqrt{d})$ dinamakan bilangan bulat kuadratik (quadratic integer), jika $\alpha=r+s \sqrt{d}$ dengan $r, s \in \mathbb{Q}$ merupakan bilangan bulat aljabar dalam lapangan $\mathbb{Q}(\sqrt{d})$

Elemen - elemen bukan unit dalam $\mathbb{Z}(\sqrt{d})$ dapat difaktorisasi menjadi elemen tak tereduksi sebagaimana dijelaskan dalam teorema berikut :

Teorema 4.14. Diberikan d square free integer. Setiap elemen tak nol yang bukan unit dalam $\mathbb{Z}(\sqrt{d})$ memiliki hasil kali elemen - elemen tak tereduksi.

Karena ada ideal dalam gelanggang $\mathbb{Z}(\sqrt{-5})$ yang bukan ideal utama 
maka gelanggang bilangan bulat $\mathbb{Z}(\sqrt{-5})$ bukan merupakan daerah ideal utama.

Proposisi 4.15. Gelanggang $\mathbb{Z}(\sqrt{-5})$ bukan merupakan daerah ideal utama.

\subsection{KAITAN ANTARA GELANGGANG BILANGAN DENGAN \\ BULAT DAERAH} FAKTORISASI TUNGGAL

Hubungan selanjutnya yang akan dipaparkan adalah antara daerah faktorisasi tunggal dengan gelanggang bilangan bulat.

Berdasarkan Teorema 4.14. $\mathbb{Z}(\sqrt{-5})$ dapat difaktorisasi, namun $\mathbb{Z}(\sqrt{-5})$ faktorisasi tidak tunggal, karena faktorisasi suatu elemen dalam $\mathbb{Z}(\sqrt{-5})$ tidaklah tunggal. Hal ini berarti elemen dalam $\mathbb{Z}(\sqrt{-5})$ dapat dinyatakan lebih dari satu faktorisasi elemen - elemen tak tereduksi, namun elemen tak tereduksi tersebut tidaklah saling berasosiasi. Sebagai contoh, elemen 6 dalam $\mathbb{Z}(\sqrt{-5})$ memiliki dua faktorisasi, yaitu $6=2 \times 3$ dan $6=(1+\sqrt{-5})(1-\sqrt{-5}) . \quad$ Dalam $\mathbb{Z}(\sqrt{-5}),(1+\sqrt{-5})$ dan $(1-\sqrt{-5})$ merupakan elemen tak tereduksi. Lebih lanjut, akan ditunjukkan bahwa 2 dan 3 elemen tak tereduksi. Misalkan $2=a b \quad$ dengan $a=r+t \sqrt{-5}$ maka
$N(a) N(b)=N(a b)=N(2)=4$

sehingga $\quad N(a)=1$ atau $\quad N(a)=2$ atau $N(a)=4$. Jika $N(a)=2$ maka $r^{2}+5 t^{2}=2$ tidak ada bilangan bulat $r$ dan $t$ yang memenuhi. Jika $N(a)=1$ maka $a$ unit. Kemudian jika $\quad N(a)=4 \quad$ maka $\quad N(b)=1$ sehingga $b$ unit. Jadi 2 elemen tak tereduksi. Lebih lanjut, 3 elemen tak tereduksi. Bukti analog dengan bukti 2 elemen tak tereduksi. Karena unit dalam $\mathbb{Z}(\sqrt{-5})$ hanya \pm 1 maka 2 dan 3 tidak berasosiasi dengan $(1+\sqrt{-5}) \quad$ dan $\quad(1-\sqrt{-5}) . \quad$ Jadi $(1+\sqrt{-5})$ bukan merupakan daerah faktorisasi tunggal.

Berdasarkan Teorema 3.3.5., menunjukkan bahwa $\mathbb{Z}(\sqrt{-5})$ merupakan gelanggang bilangan bulat. Demikian demikian, himpunan $\mathbb{Z}(\sqrt{-5})$ merupakan salah satu contoh gelanggang bilangan bulat. Jadi contoh penyangkal bahwa ada daerah Dedekind yang bukan merupakan daerah faktorisasi tunggal adalah $\mathbb{Z}(\sqrt{-5})$.

\section{KESIMPULAN DAN SARAN}

\subsection{Kesimpulan}

Berdasarkan pembahasan yang telah diberikan pada bab - bab sebelumnya, dapat ditarik kesimpulan sebagai berikut: 
1) Gelanggang bilangan bulat $O_{K}$ merupakan daerah Dedekind.

2) Gelanggang bilangan bulat $O_{K}$ yang belum tentu merupakan daerah faktorisasi tunggal, dengan contoh penyangkal $\mathbb{Z}(\sqrt{-5})$.

3) Gelanggang bilangan bulat $O_{K} \quad$ yang belum tentu merupakan daerah ideal utama, dengan contoh penyangkal $\mathbb{Z}(\sqrt{-5})$.

\subsection{Saran}

Dalam makalah ini telah
dibahas mengenai penerapan
karakteristik gelanggang bilangan
bulat $O_{K}$ untuk menyelesaikan
persamaan dua variabel derajat tinggi.




\section{REFERENSI}

Bosman, Johan, 2011, Algebraic Number Theory, Bounyer

Chow, Sam, 2011, Thesis : An Introduction ri Algebraic Number Theory, and the Class Number Formula, University of Melbourne, Australia

Ghorpade, S. R., 2002, Lecture on Topics in Algebraic Number Theory, Indian Institute of Technology Bombay, India

Hungerford, T.W., 1996, Abstract Algebra : An Introduction, Saunders College Publishing

Milne, J.S., 2009, Algebraic Number Theory, New Zealand

Murty, R., 2004, Problem in Algebraic Number Theory : Second Edition, Springer

Osserman, B., 2011, Algebraic Number Theory, Bouyer

Salustri, F.,2011, Generalized Dedekind Domain, Universita Degli Studi

Stein, W., 2005, Introduction to Algebraic Number Theory, William Stein

Stein W., 2012, Algebraic Number Theory, A Computational Approach, William Stein 